\title{
Comparison of Multiple Allergen Simultaneous Test and ImmunoCAP for the Diagnosis of Allergic Rhinitis
}

\author{
Do-Youn Kim, So Young Park, Soon Be Hong, \\ Oh Hyeong Lee, Gyeong Cheol Choi, and Jin Hee Cho \\ Department of Otorhinolaryngology-Head and Neck Surgery, College of Medicine, The Catholic University of Korea, Seoul, Korea
}

\section{알레르기 비염의 진단에서 MAST와 ImmunoCAP의 비교}

김도윤 · 박소영 · 홍순비 · 이오형 · 최경철 · 조진희

가톨릭대학교 의과대학 이비인후-두경부외과학교실

Received April 20,2017

Revised June 23, 2017

Accepted August 11, 2017

Address for correspondence

Jin Hee Cho, MD, PhD

Department of Otorhinolaryngology-

Head and Neck Surgery,

Yeouido St. Mary's Hospital,

The Catholic University of Korea,

10 63-ro, Yeongdeungpo-gu,

Seoul 07345 , Korea

Tel $+82-2-3779-2048$

Fax $+82-2-786-1149$

E-mail entcho@catholic.ac.kr
Background and Objectives Specific IgE assays are important in the diagnosis and treatment of allergic rhinitis (AR). Among the diagnostic tests of AR, multiple allergen simultaneous test (MAST) and ImmunoCAP have been frequently used as simple, safe, and economical methods. In this study, we compared the diagnostic outcomes of MAST and ImmunoCAP in patients with AR.

Subjects and Method Seventy-eight patients ( 52 men, 26 women, mean age 34.5 years: range 6-80 years), who have nasal symptoms of allergy and no clinical factors to influence the test results, underwent routine skin prick test (SPT) and MAST, and ImmunoCAP for eight major allergens. The diagnosis of AR was based on the criteria of SPT. The class 1 responses or more were regarded as positive for both MAST and ImmunoCAP. The agreements, sensitivities, and specificities of MAST and ImmunoCAP were evaluated along with the correlation between the two tests.

Results Total agreement rates of MAST and ImmunoCAP amounted to 91.5 and $92.1 \%$, respectively. The overall sensitivity and specificity of MAST were 73.4 and 95.3\%, respectively, and those of ImmunoCAP were 81.4 and $94.5 \%$, respectively. The correlations between MAST and ImmunoCAP showed statistical significance for Dermatophagoides pteronyssinus/Dermatophagoides farinae.

Conclusion Our study demonstrated the diagnostic usefulness of both MAST and ImmunoCAP in AR, especially for the most prevalent allergens of house dust mites. Moreover, ImmunoCAP, which showed higher sensitivity than MAST, can be effectively used in rhinology clinics.

Korean J Otorhinolaryngol-Head Neck Surg 2018;61(1):29-34

\section{서 론}

최근 주거환경과 식생활의 변화, 미세먼지 등으로 인한 대 기오염의 증가로 알레르기 질환이 전 세계적으로 증가하고 있

This is an Open Access article distributed under the terms of the Creative Commons Attribution Non-Commercial License (http://creativecommons.org/licenses/by-nc/4.0) which permits unrestricted non-commercial use, distribution, and reproduction in any medium, provided the original work is properly cited.
는 추세이다. ${ }^{12)}$ 알레르기 질환 중 알레르기 비염은 동반되는 증상으로 인하여 삶의 질 저하로까지 연결될 수 있는 이비인 후과 영역에서의 흔한 질환이다. 이러한 알레르기 비염을 진단 하고 치료하는 데 있어서 알레르기 유발물질인 항원을 확인하 는 것은 매우 중요하다. ${ }^{3)}$ 알레르기 비염의 진단검사로는 피부 단자검사와 특이 $\mathrm{IgE}$ 항체검사인 multiple allergen simultaneous test(MAST)와 ImmunoCAP이 주로 사용된다." 체 
내 검사인 피부단자검사는 피부 반응 정도가 혈청 $\operatorname{IgE}$ 및 특 이 $\operatorname{IgE}$ 값, 기관지유발검사와도 높은 일치율을 보여 임상에 서 널리 사용되는 검사이다. ${ }^{5)}$ 그러나 피부단자검사는 유아나 50세 이상의 노인에서 피부 반응도가 감소하고 항히스타민과 스테로이드 연고제제를 사용한 환자에게서는 적용하기 힘들 며 일중변동, 계절의 변화, 검사하는 신체 부위에 영향을 받 는다는 한계점을 지니고 있다. ${ }^{6}$ 체외 검사로는 대표적으로 MAST와 ImmunoCAP이 있으며 이 두 검사는 환자의 혈청 에서 수십 종의 항원을 동시에 측정할 수 있는 검사들로 경제 적인 선별검사로 알려져 있다. 그러나 현재까지 국내에서 알 레르기 환자에서 널리 사용되고 있는 이들 검사의 진단적 유 효성에 대해서는 국내 보고가 부족한 상황이고, 특히 MAST 와 ImmunoCAP을 알레르기 비염에서 비교한 논문은 아직 까지 없었다.

이에 본 연구는 알레르기 비염 환자를 진단하는 데 있어서 최근 가장 많이 사용하고 있는 MAST와 ImmunoCAP 검사를 피부단자검사 결과와 비교하여 그 효용성을 평가하고 나아가 임상에서의 적절한 검사 선택에 도움이 되고자 한다.

\section{대상 및 방법}

\section{대 상}

본 대학병원 이비인후과의 비과클리닉을 방문한 환자들 중에서 임상적으로 전형적인 알레르기 비염 증상을 보이며 알레르기 검사 결과에 영향을 미치는 인자들에 노출되지 않 은 환자들을 대상으로 하였다. 대상자 78명의 연령 분포는 6 세에서 80세까지 다양하였으며 연령별로는 10세 미만 4명, 10 20세 15명, 21 30세 19명, 31 40세 9명, 41 50세 13명, 51 60세 9명, 61세 이상 9명이었고, 평균 연령은 34.5세였다. 성별 분포는 남자 52명(67\%), 여자 26명(33\%)으로 남녀비 2:1 을 보였다. 이 연구는 본 병원의 임상시험심사위원회의 승인 (No. SC12TISI0060)을 받았다.

\section{검사 방법}

대상자에서 피부단자검사, MAST, ImmunoCAP을 동시에 시행하였다. 본 연구에서 피부단자검사와 MAST는 환자 부 담으로 진행하는 검사였으며, MAST를 시행하기 위해 채취 한 혈청을 통하여 ImmunoCAP을 추가로 시행하였다. ImmunoCAP은 Phadia Korea(Seoul, Korea)에서 지원받아 검 사를 진행하였다. 피부단자검사와 MAST는 흡입 알레르겐 총 24종, 수목 꽃가루(tree mix, birch, alder, beech, oak, Japanese cedar), 목초 꽃가루(grass mix, rye grass, timothy grass, orchard grass, Bermuda grass), 잡초 꽃가루(ragweed, mug- wort, Japanese hop), 곰팡이(Alternaria, Aspergillus fumiatus, Cladosporium, Candida albicans), 집먼지진드기[Dermatophagoides pteronyssinus(DP), Dermatophagoides farinae (DF)], 동물상피(cat epithelium, dog hair), 바퀴벌레(cockroach) 등에 대해 50종 이상의 항원을 검사하였고, Immu$\mathrm{noCAP}$ 의 특이 $\mathrm{IgE}$ 검사 항원은 국내에서 양성 반응이 가장 흔하다고 알려져 있는 유럽 집먼지진드기(DP), 아메리카 집 먼지진드기(DF), 고양이 털(cat epithelium), 자작나무(birch), 참나무(oak), 큰조아재비(timothy), 돼지풀(ragweed), 쑥 (mugwort) 등 8종을 선정하였다. 알레르기 비염의 진단은 피부단자검사의 진단 기준을 근거로 하였다. 환자의 전박에 피부단자검사를 시행하였으며 소아인 경우에는 등에 피부단 자검사를 시행하였다. 양성대조는 $1 \%$ 히스타민, 음성대조는 생리식염수를 사용하였고 15 분 후 팽진의 가로, 세로 직경과 홍반의 가로, 세로 직경을 측정하였다. 히스타민 양성대조와 비교하여 동일한 크기의 반응은 +++ , 양성대조의 2 배 이상 혹은 허족이 발생하였을 시에는,$++++ 50 \%$ 의 크기는 ++ , $25 \%$ 는 +, 음성대조와 같은 크기인 경우는 -로 분류하였다. 음성대조에 반응을 보이지 않는 팽진의 직경이 $3 \mathrm{~mm}$ 이상이 거나 +++ 이상의 경우를 양성으로 판정하였다. MAST는 환 자의 혈청을 분리하여 MAST-immunoblot 검사인 AdvanSure AlloScreen(LG Life Sciences, Seoul, Korea)을 사용하여 제조사의 설명서에 의하여 검사를 시행하였다. 결과 판독은 검사 기기를 통해 각각의 특이 알레르기항원에 대한 특이 $\operatorname{IgE}$ 항체값이 IU/mL 단위로 분석되어 농도 범위에 따라 class 0 6 으로 나누어졌고 class 1 미만을 음성으로 간주하였다. ImmunoCAP은 Phadia 250(Phadia AB, Uppsala, Sweden)을 사용하여 환자의 혈청에서 8 종의 항원에 대하여 제조사의 설 명서대로 검사를 시행하였고 결과는 class 0 6까지 7단계로 분류되었으며 class $1(0.35 \mathrm{kU} / \mathrm{L})$ 미만은 음성으로 간주하 였다. ${ }^{7-12)}$

\section{통계 분석}

통계분석은 유의수준 0.05에서 SPSS 18.0 통계 프로그램 (SPSS Inc., Chicago, IL, USA)을 이용하여 시행하였다. 피부 단자검사 결과를 기준으로 chi-square test를 사용하여 MAST, ImmnunoCAP의 민감도, 특이도, 그리고 일치율을 구하였 다. 민감도는 피부단자검사상 양성으로 판단된 결과 중에서 MAST, ImmunoCAP에서도 양성으로 측정한 비율로 하였 으며 특이도는 피부단자검사상 음성으로 판단된 결과 중에서 MAST, ImmunoCAP에서도 음성으로 측정한 비율로 분석 을 하였다. 일치율은 피부단자검사상의 결과가 각각의 검사 결과에서 진정한 참값을 반영하는 비율로 Kappa 분석을 이 
용하여 산출을 하였다. 본 연구에서 양성률이 가장 높았던 집먼지진드기 두 종에 대하여 MAST와 ImmunoCAP 간에 Pearson의 상관분석을 시행하였다.

\section{결 과}

피부단자검사를 시행한 78명 중 68명이 한 개 이상의 알레 르기항원에 대하여 양성 반응을 보였으나 나머지 10명은 모 든 항원에 반응을 보이지 않았다. 각각의 알레르기항원에 따 른 피부단자검사 양성률은 $\mathrm{DF}$ 가 $44.9 \%$ 로 가장 높았고 $\mathrm{DP}(43.6 \%)$, cat(14.1\%), mugwort(11.5\%)의 순서로 나타났다. MAST 양성률의 순서는 피부단자검사와 동일했으며 ImmunoCAP에서는 mugwort(16.7\%)가 cat(12.8\%)보다 높았다 (Table 1).

\section{MAST와 ImmunoCAP의 일치율, 민감도 및 특이도}

피부단자검사의 양성과 음성을 기준으로 MAST와 ImmunoCAP 검사의 일치율, 민감도 및 특이도를 각각의 항원과

Table 1. Positive rate of each allergen detected by skin prick test, MAST, and ImmunoCAP

\begin{tabular}{lccc}
\hline \multirow{2}{*}{ Allergen } & \multicolumn{3}{c}{ No. (\%) of positive reaction } \\
\cline { 2 - 4 } & Skin prick test & MAST & ImmunoCAP \\
\hline DF & $35(44.9)$ & $41(52.6)$ & $42(53.8)$ \\
DP & $34(43.6)$ & $36(46.2)$ & $37(47.4)$ \\
Cat & $11(14.1)$ & $12(15.4)$ & $10(12.8)$ \\
Mugwort & $9(11.5)$ & $4(5.1)$ & $13(16.7)$ \\
Birch & $6(7.7)$ & $1(1.3)$ & $3(3.8)$ \\
Oak & $6(7.7)$ & $0(0.0)$ & $5(6.4)$ \\
Timothy & $6(7.7)$ & $3(3.8)$ & $4(5.1)$ \\
Ragweed & $6(7.7)$ & $3(3.8)$ & $8(10.3)$ \\
\hline
\end{tabular}

MAST: multiple allergen simultaneous test, DF: Dermatophagoides farinae, DP: Dermatophagoides pteronyssiunus

Table 2. Agreement, sensitivity, and specificity of MAST on the basis of the diagnostic criteria of skin prick test

\begin{tabular}{lccc}
\hline \multicolumn{1}{c}{ Allergen } & Agreement & Sensitivity & Specificity \\
\hline DF & 87.2 & $94.3(33 / 35)$ & $81.4(35 / 43)$ \\
DP & 87.2 & $88.2(30 / 34)$ & $86.4(38 / 44)$ \\
Cat & 91.0 & $66.7(8 / 12)$ & $95.5(63 / 66)$ \\
Mugwort & 93.6 & $44.4(4 / 9)$ & $100.0(69 / 69)$ \\
Birch & 93.6 & $100.0(1 / 1)$ & $93.5(72 / 77)$ \\
Oak & 92.3 & $0(0 / 6)$ & $100.0(72 / 72)$ \\
Timothy & 93.6 & $33.3(2 / 6)$ & $98.6(71 / 72)$ \\
Ragweed & 93.6 & $33.3(2 / 6)$ & $98.6(71 / 72)$ \\
Overall & 91.5 & $73.4(80 / 109)$ & $95.3(491 / 515)$ \\
\hline
\end{tabular}

Data are presented as percentage (number of positive results/ numbers tested). MAST: multiple allergen simultaneous test, DF: Dermatophagoides farinae, DP: Dermatophagoides pteronyssiunus
전체 항원에 대하여 산출하였다. 모든 알레르기항원을 포함 한 전체적인 일치율은 MAST에서 $91.5 \%$, ImmunoCAP에서 $92.1 \%$ 를 보였다. 민감도는 MAST가 $73.4 \%$, ImmunoCAP이 $81.4 \%$ 를 보였고, 특이도는 MAST가 $95.3 \%$, ImmunoCAP이 $94.5 \%$ 를 보였다. 공통적으로 높은 양성률을 보인 $\mathrm{DP}$ 와 $\mathrm{DF}$ 에 대하여 일치율, 민감도와 특이도를 비교해 보았다. DP에 대해서 MAST는 일치율 $87.2 \%$, 민감도 $88.2 \%$, 특이도 $86.4 \%$ 를 보였고, $\mathrm{DF}$ 에 대해서는 일치율 $87.2 \%$, 민감도 $94.3 \%$, 특 이도 $81.4 \%$ 를 보였다. ImmunoCAP의 DP에 대한 일치율, 민 감도, 특이도는 각각 $88.5,88.2,88.6 \%$ 를 보였으며 $\mathrm{DF}$ 에 대 해서는 각각 91.0, 100, 83.7\%를 나타냈다(Table 2 and 3).

\section{MAST와 ImmunoCAP의 상관관계}

$\mathrm{DP}$ 와 $\mathrm{DF}$ 에 대한 특이 $\mathrm{IgE}$ 항체가 MAST와 ImmunoCAP 검사에서 어느 정도의 상관성을 갖는지 알아보기 위하여 Pearson 상관분석을 시행하였다. 상관계수는 DP에서 $0.792(p<$ $0.001), \mathrm{DF}$ 에서 $0.752(p<0.001)$ 로 두 항원 모두에서 유의한 양의 상관관계를 보였다(Fig. 1).

\section{고 찰}

알레르기 비염은 특정 항원에 대하여 $\operatorname{IgE}$ 를 매개로 하는 코와 부비동 점막의 제 1 형 과민반응을 보이는 염증성 질환이 다. ${ }^{13)}$ 전 세계적으로 알레르기 비염의 유병률은 날로 증가하 는 추세에 있으며 최근 국내 알레르기 비염의 유병률은 33\% 정도로 보고되고 있다. ${ }^{2}$ 정확한 진단을 내리는 것은 알레르 기 비염을 치료하는 데 있어서 매우 중요하나 실제 임상에서 알레르기 비염을 다른 비염과 명확히 구별하기는 어려운 일이 다. 알레르기 비염을 진단하는 데에는 환자의 증상 및 신체 검사 소견뿐만 아니라 객관적인 진단검사가 꼭 필요하다. ${ }^{14)}$

Table 3. Agreement, sensitivity, and specificity of ImmunoCAP on the basis of the diagnostic criteria of skin prick test

\begin{tabular}{lccr}
\hline \multicolumn{1}{c}{ Allergen } & Agreement & Sensitivity & Specificity \\
\hline DF & 91.0 & $100.0(35 / 35)$ & $83.7(36 / 43)$ \\
DP & 88.5 & $88.2(30 / 34)$ & $88.6(39 / 44)$ \\
Cat & 93.6 & $72.7(8 / 11)$ & $97.0(65 / 67)$ \\
Mugwort & 82.9 & $77.8(7 / 9)$ & $91.3(63 / 69)$ \\
Birch & 96.2 & $50.0(3 / 6)$ & $100.0(72 / 72)$ \\
Oak & 93.6 & $50.0(3 / 6)$ & $97.2(70 / 72)$ \\
Timothy & 92.3 & $33.3(2 / 6)$ & $97.2(70 / 72)$ \\
Ragweed & 92.3 & $66.7(4 / 6)$ & $94.4(68 / 72)$ \\
Overall & 92.1 & $81.4(92 / 113)$ & $94.5(483 / 511)$
\end{tabular}

Data are presented as percentage (number of positive results/ numbers tested). MAST: multiple allergen simultaneous test, DF: Dermatophagoides farinae, DP: Dermatophagoides pteronyssiunus 


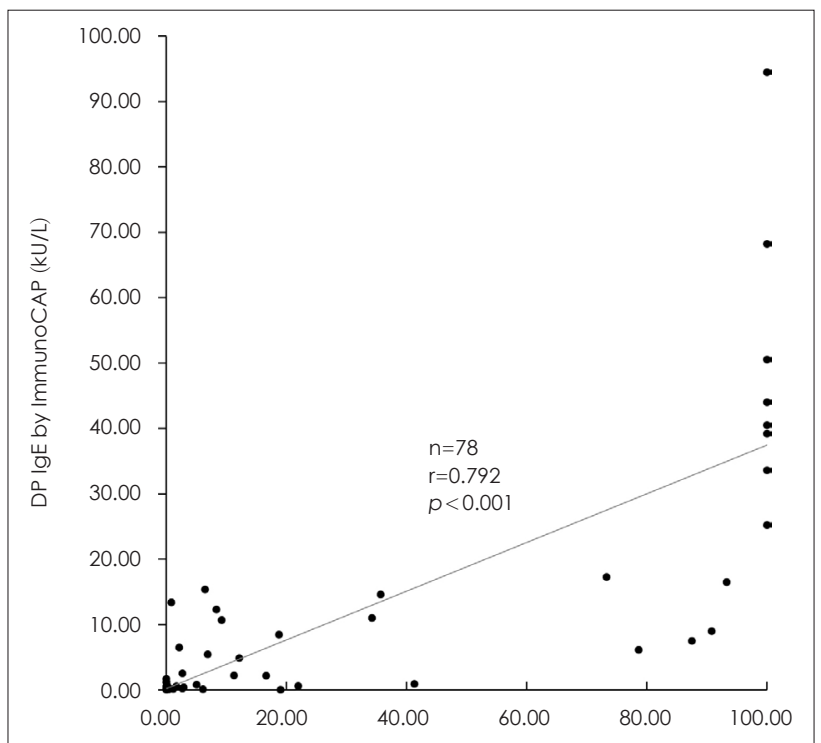

A

DP IgE by MAST (IU/mL)

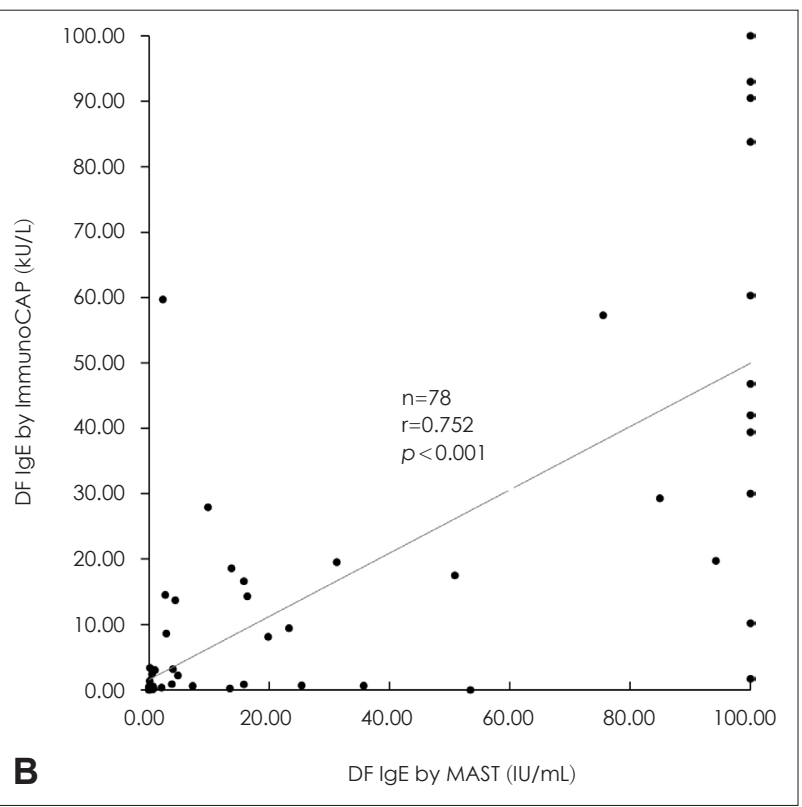

Fig. 1. Correlations between MAST and ImmunoCAP for DP $(n=78, r=0.792, p<0.001)(A)$ and $D F(n=78, r=0.752, p<0.001)(B)$. MAST: multiple allergen simultaneous test, DP: Dermatophagoides pteronyssiunus, DF: Dermatophagoides farinae.

지금까지 알려진 진단검사법으로는 체내 반응검사인 피부단 자검사와 유발반응검사, 체외 검사인 radioallergosorbent test(RAST), MAST, 그리고 ImmunoCAP 등에 의한 특이 $\mathrm{IgE}$ 항체를 측정하는 방법이 있는데, 임상에서 주로 사용되 는 검사로는 피부단자검사, MAST, ImmunoCAP을 들 수 있다. 최근 발표된 메타분석연구에서 피부단자검사의 민감도 는 68 100\%, 특이도는 70 91\%로 다양하게 보고되고 있다. ${ }^{15)}$ 알레르기 질환 진단 시 피부단자검사에서 양성 반응을 나타 낸다고 해서 그대로 기인 항원으로 단정 지을 수 없어 결과 해석에 이견이 많고, 양성 기준 또한 검사자마다 다르다. 또한 스테로이드 연고제나 항히스타민제의 사용, 피검자의 연령, 검사 부위 등 여러가지 요인들이 검사 결과에 영향을 미친다. 이러한 제한에도 불구하고 피부반응검사는 시행하기 간편하 며 검사 비용이 비교적 저렴하고 안전하며 많은 종류의 항원을 한 번에 검사할 수 있다는 장점을 지니고 있어 국내에서 널리 이용되고 있다. 면역 치료가 필요한 경우에는 혈중 특이 $\mathrm{IgE}$ 항체치를 측정하기 위한 검사가 필요하다. 과거 30년 전 최초 로 개발된 RAST는 혈청 내 특이 $\mathrm{IgE}$ 를 측정하는 새로운 알 레르기 질환의 검사법이었다. ${ }^{16)}$ 이후 개발된 MAST와 ImmunoCAP 시스템은 개별 항원에 대한 검사인 RAST와 달리 수 십 종의 항원을 동시에 측정할 수 있어 경제적인 선별검사로 현재 임상에서 널리 사용되고 있다. 이러한 검사들은 항히스 타민제와 같은 약물 사용에 영향을 덜 받고, 3 세 이하의 소아 나 피부반응검사에서 반응을 구별하기 힘든 노인에게서도 시 행할 수 있으며, 피부 자극으로 인한 고통이 없고 피부묘기증
등의 피부 질환이 있는 환자에서도 시행할 수 있다는 장점을 가지고 있다. 국내에서는 검사실 검사로 본 연구에서 사용된 ImmunoCAP 시스템(Phadia AB)과 AdvanSure AlloScreen (LG Life Sciences) 이외에도 항원 항체 결합을 화학 발광물 질을 이용하여 판독하는 MAST CLA(Hitachi Chemical Diagnostics Inc., Mountain View, CA, USA), immunoblot 방법 을 이용한 Allergy Screen(r-biopharm, Darmstadt, Germany), Polycheck Allergy(Biocheck GmbH, Munster, Germany) 등이 사용되고 있다.,10,17) 하지만 앞서 열거한 알레르기항원 특이 $\operatorname{IgE}$ 검사는 표준화된 참고방법이 없어 in vivo 검사인 피부단자검사가 in vitro 검사의 평가 기준으로 널리 사용되 고 있다. ${ }^{8-10,18-21)}$ 이에 본 연구에서도 피부단자검사 결과를 기 준으로 ImmunoCAP 및 MAST 검사를 평가하였다.

본 연구에서는 과거의 연구들과 동일하게 세 가지 검사 모두 에서 DF와 DP가 가장 높은 양성률을 보였으나, 다른 항원들 의 양성률은 발표된 연구마다 다르게 보고되고 있으며 본 연 구에서도 검사별로 차이를 보였다. ${ }^{8-10,19-23)}$ 그 원인으로는 검 사 방법에 따른 알레르기항원의 원료 차이와 제조법, 검사를 시행한 지역과 시대의 차이 등 여러 가지 요인들과 더불어 양 성 판정 기준이 검사 결과에 큰 영향을 미칠 수 있다는 점을 들 수 있다. MAST에서 알레르기 유무를 판단하는 최소 기 준치는 과거 연구들에서는 class 2 이상을 알레르기 반응이 있는 것으로 판정하였으나, 현재에는 환자의 증상과 상관관 계를 고려하여 class 1 이상을 양성 판정 기준으로 한다. ${ }^{7-12)}$ ImmunoCAP은 통상적으로 측정된 농도가 기준치 $0.35 \mathrm{kU} /$ 
L(class 1) 이상인 경우를 알레르기 양성으로 판단한다. 본 연 구에서도 두 검사에서 각각 class 1 이상의 반응을 보이는 경 우를 알레르기 양성 반응으로 판정하였다. 그러나 최근 발표 된 연구들에서 ImmunoCAP의 양성 기준치를 $0.10 \mathrm{kU} / \mathrm{L}$ 로 낮추어 제시하고 $0.10 \sim 0.35 \mathrm{kU} / \mathrm{L}$ 의 수치도 알레르기 반응 이 있는 것으로 발표하고 있다. ${ }^{24,25)}$ 따라서 이러한 검사들의 기준치와 임상적 연관성에 대해서는 앞으로 추가적인 연구가 필요할 것으로 생각된다. 또한 본 연구에서는 알레르기 검사 결과에 크게 영향을 미칠 수 있는 시간적, 환경적인 요소를 배제하여 세 가지 검사를 동시에 시행해 결과를 비교하였다 는 점에서 결과가 시사하는 바가 크다고 볼 수 있다.

피부단자검사의 양성과 음성을 기준으로 한 모든 알레르 기항원에 대한 MAST의 민감도는 $73.4 \%$, 특이도는 $95.3 \%$ 였 으며, ImmunoCAP은 민감도 $81.4 \%$, 특이도 $94.5 \%$ 였다. 그 러나 항원에 따른 민감도와 특이도의 차이가 커서 전체 항원 에 대한 수치보다는 알레르기 질환의 주요 항원이자 양성률 이 가장 높은 $\mathrm{DF}$ 와 $\mathrm{DP}$ 의 결과를 비교하는 것이 더 의의가 있을 것으로 생각되었다. $\mathrm{DF}$ 에 대한 MAST의 일치율, 민감 도, 특이도는 각각 87.2, 94.3, 81.4\%였고, ImmunoCAP은 각 각 91.0, 100.0, 83.7\%로 두 검사가 모두 높은 값을 보이며 특 히 민감도가 매우 높았고, 세 가지 지표 모두 ImmunoCAP 이 MAST보다 더 높은 양상을 보였다. DP의 경우에는 MAST와 ImmunoCAP이 일치율, 민감도, 특이도가 모두 비 슷한 값을 보였다. 반면에 피부단자검사에서 양성률이 낮은 일부 항원에서는 민감도, 특이도가 $0 \%$ 또는 $100 \%$ 를 보였는 데 이는 피부단자시험에서 양성 판정을 받은 경우가 거의 없 었기 때문이며 대상자가 더 많아진다면 좀 더 정확한 연구가 가능할 것으로 생각된다. 과거 연구들에서도 알레르기 질환 을 진단하는 데 있어 ImmunoCAP과 MAST들은 약간의 차 이는 있지만 거의 비슷한 일치도, 민감도, 특이도를 보인다고 보고하고 있다. ${ }^{10,21,26)}$ 이는 본 연구에서 밝힌 두 검사 간의 유 의한 상관관계에 의해서도 뒷받침될 수 있다.

결론으로, 8종의 알레르기항원에 대한 전체적인 일치율과 특이도는 MAST와 ImmunoCAP에서 모두 90\% 이상으로 그 값이 비슷했고, 민감도는 90\%에 달하지 못하였으나 ImmunoCAP에서 더 높았다. 피부단자검사의 양성률이 높은 항원 일수록 두 검사 모두에서 세 가지 지표가 고르게 높은 값을 보 였다. 저자들은 본 연구를 통하여 MAST와 ImmunoCAP이 알레르기 비염의 진단과 치료에 있어서 정확하고 간편한 검 사임을 확인하였으며, 민감도가 큰 ImmunoCAP은 앞으로 임상에서 널리 활용될 수 있는 유용한 검사법으로 생각된다.

\section{Acknowledgments}

We thank for Phadia Korea for the support of ImmunoCAP system to be used in this study.

\section{REFERENCES}

1) Blaiss MS. Allergic rhinitis: direct and indirect costs. Allergy Asthma Proc 2010;31(5):375-80.

2) Suh M, Kim HH, Sohn MH, Kim KE, Kim C, Shin DC. Prevalence of allergic diseases among Korean school-age children: a nationwide cross-sectional questionnaire study. J Korean Med Sci 2011;26(3): 332-8.

3) Wheatley LM, Togias A. Allergic rhinitis. N Engl J Med 2015;372 (5):456-63.

4) Douglass JA, O'Hehir RE. 1. Diagnosis, treatment and prevention of allergic disease: the basics. Med J Aust 2006;185(4):228-33.

5) Ownby DR. Allergy testing: in vivo versus in vitro. Pediatr Clin North Am 1988;35(5):995-1009.

6) Van Asperen PP, Kemp AS, Mellis CM. Skin test reactivity and clinical allergen sensitivity in infancy. J Allergy Clin Immunol 1984;73(3): 381-6.

7) Constable DW, Harris RI, Ganderton MA. Statistical problems in assessing the true value of new in vitro diagnostic tests, with special reference to the chemiluminescent assay (CLA, MAST). J Investig Allergol Clin Immunol 1991;1(3):169-78.

8) Ho TM, DeBruynne J, Ahamad M, Darussamin H. Evaluation of the MAST CLA allergy system for diagnosis of allergies to house dust mites and cats. Asian Pac J Allergy Immunol 1997;15(3):123-6.

9) Jang WR, Nahm CH, Kim JH, Lim DH, Jang TY, Moon YS, et al. [Allergen specific IgE measurement with Polycheck Allergy: comparison of three multiple allergen simultaneous tests]. Korean J Lab Med 2009;29(5):465-72.

10) Jeong S, Jang GC, Cho NJ, Han MS, Kim HS, Sun JY, et al. Analysis of polycheck allergy results of the recent two years: comparison with skin prick test and ImmunoCAP. Lab Med Online 2012;2(3):13947.

11) Nepper-Christensen S, Backer V, DuBuske LM, Nolte H. In vitro diagnostic evaluation of patients with inhalant allergies: summary of probability outcomes comparing results of CLA- and CAP-specific immunoglobulin E test systems. Allergy Asthma Proc 2003;24(4): 253-8.

12) Scolozzi R, Boccafogli A, Vicentini L, Baraldi A, Bagni B. Correlation of MAST chemiluminescent assay (CLA) with RAST and skin prick tests for diagnosis of inhalant allergic disease. Ann Allergy 1989; 62(3):193a-b.

13) Bousquet J, Schünemann HJ, Samolinski B, Demoly P, BaenaCagnani $\mathrm{CE}$, Bachert $\mathrm{C}$, et al. Allergic Rhinitis and its Impact on Asthma (ARIA): achievements in 10 years and future needs. J Allergy Clin Immunol 2012;130(5):1049-62.

14) Bousquet J, Khaltaev N, Cruz AA, Denburg J, Fokkens WJ, Togias A, et al. Allergic Rhinitis and Its Impact on Asthma (ARIA) 2008 update (in collaboration with the World Health Organization, GA(2) LEN and AllerGen). Allergy 2008;63 Suppl 86:8-160.

15) Nevis IF, Binkley K, Kabali C. Diagnostic accuracy of skin-prick testing for allergic rhinitis: a systematic review and meta-analysis. Allergy Asthma Clin Immunol 2016;12:20.

16) Wide L, Bennich H, Johansson SG. Diagnosis of allergy by an in-vitro test for allergen antibodies. Lancet 1967;2(7526):1105-7.

17) Lee JH, Park KH, Kim HS, Kim KW, Sohn MH, Kim CH, et al. Specific IgE measurement using AdvanSure ${ }^{\circledR}$ system: comparison of detection performance with ImmunoCAP ${ }^{\circledR}$ system in Korean allergy patients. Clin Chim Acta 2012;413(9-10):914-9.

18) Contin-Bordes C, Petersen A, Chahine I, Boralevi F, Chahine H, Taïeb A, et al. Comparison of ADVIA Centaur and Pharmacia UniCAP tests 
in the diagnosis of food allergy in children with atopic dermatitis. Pediatr Allergy Immunol 2007;18(7):614-20.

19) Kim JH, Roh JY, Lee JR. Analysis of ImmunoCAP(R) ISAC results of chronic spontaneous urticaria patients: comparison with skin prick and the MAST-EIA tests. Korean J Dermatol 2015;53(9):684-92.

20) Nam YH, Jeon DS, Lee SK. Comparison of skin prick test and serum specific IgE measured by ImmunoCAP system for various inhalant allergens. Allergy Asthma Respir Dis 2015;3(1):47-53.

21) Wolthers OD, Staberg M. The usefulness of the multiple allergen simultaneous test-chemiluminescent as compared to the Phadia Immunocap IgE test panel system in children and adolescents. Recent Pat Inflamm Allergy Drug Discov 2013;7(1):96-9.

22) Han M, Shin S, Park H, Park KU, Park MH, Song EY. Comparison of three multiple allergen simultaneous tests: RIDA allergy screen, MAST optigen, and polycheck allergy. Biomed Res Int 2013;2013:
340513.

23) Kim HA, Ye YM, Hur GY, Kim SH, Suh CH, Nahm DH, et al. Comparative study of ImmunoCAP and ELISA for detecting allergen specific IgE to Japanese hop pollen and two spotted spider mite. Clin Immunol 2006;26(2):129-35.

24) Szefler SJ, Wenzel S, Brown R, Erzurum SC, Fahy JV, Hamilton RG, et al. Asthma outcomes: biomarkers. J Allergy Clin Immunol 2012; 129(3 Suppl):S9-23.

25) Cain TW, Ford J, Dolen WK. A low-level method for measurement of specific immunoglobulin E antibody in serum. Allergy Clin Immunol Int-J World Allergy Org 2006;18(6):230-3.

26) Lee JH, Park HJ, Park KH, Jeong KY, Park JW. Performance of the PROTIA ${ }^{\mathrm{TM}}$ Allergy-Q ${ }^{\circledR}$ System in the detection of allergen-specific IgE: a comparison with the ImmunoCAP ${ }^{\circledR}$ system. Allergy Asthma Immunol Res 2015;7(6):565-72. 